\title{
O dialogismo e a construção do ethos no discurso publicitário
}

The dialogism and the construction of the ethos in the publicity discourse

El diálogo y la construccion del ethos en el discurso publicitário

Juliana Geórgia Gonçalves de Araújo $\oplus^{1}$

Lia Raquel Vieira de Andrade ${ }^{1}$

1 Universidade da Integração Internacional da Lusofonia Afro-Brasileira, Redenção, CE, Brasil.

$-\diamond$

\section{RESUMO}

Este trabalho tem como propósito analisar a capacidade de persuasão da publicidade frente ao consumidor, identificando as estratégias utilizadas à luz da Análise do Discurso de linha francesa. Selecionamos para a nossa análise anúncios impressos do detergente em pó OMO. Verificamos a construção do ethos no discurso publicitário como uma estratégia manipulativo-persuasiva utilizada pelo enunciador para persuadir o seu leitor-consumidor. A imagem foi criada para que o interlocutor possa se identificar com o ethos de uma mãe que quer proporcionar momentos felizes para o filho, mas sem se preocupar com as consequências dessas brincadeiras, como as manchas nas roupas. Desse modo, não será apenas com o quadro cênico que o leitor-consumidor irá se envolver, mas, fundamentalmente, com a cenografia criada pelo anúncio.

Palavras-chave: Anúncio publicitário. Ethos. Dialogismo.

\section{ABSTRACT}

The french Discourse Analysis is used to analyze the persuasion strategies to draw the consumers' attention in the OMO detergent advertizing. We identified the construction and use of the image of an ethos in the discourse of the advert as manipulative-persuasive tactics used by the enunciator to convince the reader about the quality of the product. We found that the image was created aiming some interlocutor that might get identified with the ethos of mothers carrying her happy children, without worrying about stains on the cloths. Thus, the consumer is lead to get involved with the scenography rather the scenic frame of the advertisement.

Keywords: Advertisement. Ethos. Dialogism.

\section{RESUMEN}

Este trabajo tiene como objetivo analisar la capacidad de persuasión de la publicidad frente al consumidor, identificando las estrategias utilizadas en el análisis del discurso de la línea francesa. Seleccionamos para nuestro análisis anuncios impresos del detergente OMO. Verificamos la construcción del ethos en el discurso publicitario como una estrategia manipuladora-persuasiva utilizada por el enunciador para persuadir sulector-consumidor. La imagen fue creada para que el interlocutor se identifique con el ethos de una madre que quiere proporcionar momentos felices para su hijo, pero sin se preocupar con las consecuencias de los juegos, como las manchas en las ropas. De esa manera, no será apenas como una escena donde el lector-consumidor se envolverá, pero fundamentalmente con el escenário criado por el anuncio.

Palabras clave: Anuncio publicitario. Ethos. Diálogo. 


\section{Introdução}

A publicidade utiliza cada vez mais estratégias, no intuito de obter uma identificação do público para com os produtos anunciados, estabelecendo, a partir daí, uma relação, que se deve tornar familiar e, muitas vezes, quase íntima, aos olhos do consumidor. Desse modo, a publicidade trabalha com a sedução, isso porque ela não tem a autoridade de ordenar, "compre este produto", ela usa a manipulação disfarçada, convencendo e seduzindo o consumidor para que esse, depois de manipulado, considere o produto uma necessidade em sua vida; desse modo, objetivamos analisar a construção do ethos no discurso publicitário como uma estratégia manipulativopersuasiva utilizada pelo enunciador para persuadir seu leitor-consumidor.

Selecionamos para a nossa análise anúncios publicitários veiculados de forma impressa do detergente em pó OMO, também analisados por Gomes (2009). O trabalho está situado no âmbito da Análise do Discurso de linha francesa.

Publicidades veiculadas em mídia impressa são usualmente dotadas de linguagem verbal e não verbal (visual). Com isso, trazem mecanismos argumentativo-persuasivos e efeitos de sentido ímpares a considerar. Desse modo, iremos analisar a articulação entre a linguagem verbal e a linguagem não verbal e as estratégias manipulativo-persuasivas geradas nesse discurso.

A nossa pesquisa está organizada da seguinte forma: inicialmente, apresentamos as concepções de dialogismo e de ethos que nortearam este estudo; em seguida, tecemos algumas considerações acerca do discurso publicitário; depois, realiza-se a análise propriamente dita; e, por fim, as considerações finais.

\section{Considerações sobre o conceito de dialogismo}

O eixo norteador de todo o pensamento de Bakhtin caracteriza-se pela interação verbal e o seu caráter dialógico. Disso resulta a abordagem histórica e viva da língua e o tratamento sociológico das enunciações. A língua é vista como um fenômeno social, histórico e ideológico, por consequência, "a comunicação verbal não poderá jamais ser compreendida e explicada fora desse vínculo com a situação concreta" (BAKHTIN, 1981, p. 124).

Bakhtin (2000) considera o dialogismo o princípio constitutivo da linguagem e a condição do sentido do discurso. $\mathrm{O}$ autor insiste no fato de que o discurso não é individual: $1^{\circ}$ ) não é individual porque é construído entre, pelo menos, dois interlocutores que, por sua vez, são seres sociais; e $2^{\mathrm{O}}$ ) não é individual porque se constrói como um diálogo entre discursos, ou seja, porque mantém relações com outros discursos.

Nesse sentido, Bakhtin (2000) entende dialogismo como a presença do discurso de outrem no discurso de um enunciador, fazendo com que um enunciado seja uma espécie de réplica a outros enunciados, como em um diálogo. Ou seja, os sujeitos não possuem neles mesmos o conhecimento do que é veiculado pelo ato da enunciação, mas é na interação desses sujeitos, ou seja, é na dialogicidade que o conhecimento é construído. Com efeito, é por meio do diálogo que se confirma a unicidade do "eu". Desse modo, um sujeito não pode ser considerado isoladamente, ele constrói-se sempre no processo da sua interrelação com outros. O diálogo, por sua vez, constitui uma das formas mais importantes da interação verbal. A palavra "diálogo" passa a ser compreendida em um sentido mais amplo, isto é, não apenas como a comunicação oral, ou seja, uma conversa face a face, mas toda comunicação verbal.

Podemos afirmar, de acordo Silva (2004), que o dialogismo em Bakhtin, opera em vários níveis: nas relações entre interlocutores, nas relações do texto com outros discursos e textos e do texto com o contexto.

No diálogo, considerado em seu primeiro nível, ou seja, relações entre interlocutores, aparecem três elementos: o falante, o interlocutor e a relação entre os dois. Bakhtin ainda reconhece a existência de um outro participante para cada ato de fala: o destinatário superior. O destinatário superior, segundo Jobin e Souza (1997), é aquele que antecipa a compreensão de um enunciado, quer dizer, prevê a sua compreensão, em um espaço metafísico ou em um tempo historicamente distante.

O locutor mantém relação com os enunciados de outros locutores e não somente com o objeto da enunciação. Os enunciados estão sempre em busca de uma resposta do outro. "Ter um destinatário, dirigir-se a alguém, é uma particularidade constitutiva do enunciado, sem a qual não há, e não poderia haver, enunciado" (BAKHTIN, 2000, p.325). O destinatário participa ativamente na cadeia discursiva, sendo o enunciado construído em função da sua resposta. "A palavra é um território compartilhado, quer pelo expedidor, quer pelo destinatário" (BAKHTIN, 1981, p. 85). Sendo assim, uma intenção enunciativa é sempre mediada pelas intenções dos outros.

O enunciado é também sempre uma resposta a um enunciado anterior, ou seja, há relação entre o texto com outros discursos e textos, o que caracteriza o segundo nível de operação do dialogismo.

Brait (1996) sintetiza a dupla função do dialogismo bakhtiniano, ou seja, os dois primeiros níveis de operação que mencionamos acima: 
o dialogismo diz respeito ao permanente diálogo, nem sempre simétrico e harmonioso, existente entre os diferentes discursos que configuram uma comunidade, uma cultura, uma sociedade. É nesse sentido que podemos interpretar o dialogismo como o elemento que instaura a constitutiva natureza interdiscursiva da linguagem. Por um outro lado, o dialogismo diz respeito às relações que se estabelecem entre o eu e o outro nos processos discursivos instaurados historicamente pelos sujeitos, que por sua vez instauram-se e são instaurados por esses discursos (BRAIT, 1996, p. 78).

Podemos ainda comentar um terceiro nível de operação do dialogismo: nas relações entre o texto e o contexto. Toda enunciação tem um aspecto linguístico, que se refere a um enunciado pré-existente, e o contextual que é único, tendo como referência novos enunciados. $\mathrm{O}$ enunciado se produz em um contexto que é sempre social e ligado a uma situação concreta, não sendo necessária a presença do interlocutor, mas pressupondo a sua existência. Para Bakhtin o homem e a linguagem estão sócio-historicamente situados e, portanto, o significado é construído a partir da relação ou diálogo entre o discurso e a situação imediata ou o contexto mais amplo em que estão envolvidos os participantes.

\section{Considerações sobre o conceito de ethos}

O ethos não é um assunto recente, desde a antiguidade vem sendoestudado. Os estudos de Aristóteles na Arte Retórica e Arte Poética são os primeiros a tratar desse fenômeno. Segundo o filósofo grego, há três características positivas que o orador deveria construir a partir de seu discurso: prhonesis, que diria respeito ao caráter de ponderação, sabedoria e racionalidade com que se apresenta um orador; areté, que diria respeito à sinceridade e simplicidade do orador; e eunóia, que se definiria pela imagem de gentileza e agradabilidade que um orador mostra de si.

A retórica antiga serviu de ponto de partida para outros estudos acerca do ethos, contudo, apenas nos anos 1980, essa categoria passou a ser explorada em termos pragmáticos ou discursivos. Ducrot (1987) retomou os estudos aristotélicos sobre o ethos, conceituando esse fenômeno com a sua distinção entre o "locutor L" (=o enunciador) e o "locutor-lambda" ( $=$ o locutor enquanto ser do mundo), que atravessava a distinção dos pragmatistas entre mostrar e dizer. $\mathrm{O}$ ethos, segundo o autor, se mostra no ato da enunciação, ele não é dito no enunciado.

Maingueneau (2005) também retomou a retórica antiga, contudo, ampliando o conceito de ethos. Ao afirmar que o ethos, diferentemente do que pensava a retórica clássica, pertence também ao texto escrito, não estando restrito somente à oralidade, Maingueneau amplia e reformula esse conceito. Segundo o autor, o ethos apresenta um caráter e uma corporalidade, reveladas através do "tom" que o enunciador dá do seu discurso ao coenunciador. Pode-se dizer, então, que o tripé tom/ caráter/corporalidade constitui o cerne da concepção de Maingueneau sobre ethos.

O tom é definido, por Maingueneau (2001), como sendo a voz que atesta o dito, possibilitando ao coenunciador formar uma imagem do enunciador (e não, é claro, do corpo do produtor efetivo do texto), através de indícios textuais de várias ordens. Essa imagem exerce o papel de "fiador" do que é dito. O fiador apresenta um caráter e uma corporalidade. O "caráter" corresponde a este conjunto de traços psicológicos que o leitor ouvinte atribui espontaneamente à figura do enunciador, em função do seu modo de dizer. Deve-se dizer o mesmo a propósito da "corporalidade" que remete a uma representação do corpo do enunciador da formação discursiva. Corpo que não é oferecido ao olhar, que não é uma presença plena, mas uma espécie de "fantasma" induzido pelo destinatário como correlato de sua leitura, conforme defende o autor.

Se os dois elementos do ethos, quais sejam, o caráter e a corporalidade, forem integrados à discursividade, segundo Maingueneau (1997a, p.48), o discurso passa a ser indissociável da forma pela qual "toma corpo". Desse modo, o "caráter" está associado a "um feixe de traços psicológicos" e a "corporalidade" está relacionada a "uma compleição do corpo do fiador" inseparável de uma maneira de se vestir e se movimentar no espaço social.

O autor introduz a noção de incorporação, ou seja, a mescla essencial entre uma formação discursiva e seu ethos que ocorre através do procedimento enunciativo. Esse conceito pode ser descrito da seguinte forma:

- a enunciação leva o co-enunciador a conferir um ethos ao fiador, ela lhe dá corpo;

- o co-enunciador incorpora, assimila, desse modo, um conjunto de esquemas que definem para um dado sujeito, pela maneira de controlar seu corpo, de habitálo, uma forma específica de se inscrever no mundo;

- essas duas primeiras incorporações permitem a constituição de um corpo, o da comunidade imaginária dos que comungam na adesão a um mesmo discurso (MAINGUENEAU, 2001, p. 99).

O sujeito enunciador é construído pelo discurso, por meio das marcas visíveis na enunciação. E o ethos se constrói no conjunto, na totalidade das marcas enunciativas. $\mathrm{E}$ as marcas enunciativas possibilitam a emergência de uma imagem que determina os processos de interação e a configuração da identidade.

Não podemos deixar de ressaltar a relação entre o ethos e as cenas da enunciação. Segundo Maingueneau 
(1997b), instaura-se, na interação entre enunciador e coenunciador no discurso, uma cena enunciativa. Ambos, valendo-se de suas formações discursivas, assumem uma identidade no discurso, mas uma identidade construída no e pelo discurso. Desse modo, resulta uma estreita relação entre ethos e cena enunciativa.

Segundo Maingueneau (2001), a cena de enunciação de um texto envolve três cenas. A primeira, denominada de cena englobante, corresponde ao tipo de discurso (religioso, político, publicitário etc.). A segunda, chamada cena genérica, está relacionada ao gênero (anúncio, bilhete, poema etc.) e a terceira, a cenografia, com a qual se defronta diretamente o coenunciador, é instituída no próprio enunciado. Esta última engloba uma topografia (um lugar) e uma cronografia (um momento), que não faze referência exatamente a um lugar e a um momento empíricos, mas são construtos construídos e legitimados na e pela enunciação; há, ainda, no âmbito da cenografia, um enunciador e um coenunciador (imagens de um eu e um tu construídas na enunciação).

Se a interação está relacionada com o processo de comunicação, segundo Barros (2003), está também ligada à construção de sentidos e de identidades. O ethos, portanto, é construído no processo de interação verbal, no funcionamento da linguagem, nas diferentes escolhas lexicais realizadas pelos falantes. Desse modo, podemos resumir a noção de ethos de acordo com Maingueneau:

O ethos é uma categoria social, uma noção discursiva, ele se constitui por meio do discurso, não é uma "imagem" do locutor exterior à fala; o ethos é fundamentalmente um processo interativo de influência sobre o outro; o ethos é uma noção fundamentalmente híbrida (sociodiscursiva), um comportamento socialmente avaliado, que não pode ser apreendido fora de uma situação comunicativa precisa, ela própria integrada a uma conjuntura sócio-histórica determinada (MAINGUENEAU, 2001, p. 139).

\section{0 anúncio publicitário}

Conforme Carvalho (2000, p. 15), o anúncio constitui o canal de publicidade por excelência, estabelecendo uma ligação direta entre a oferta e a procura. Além disso, em termos de mensagem publicitária, o anúncio (em jornal, revista, outdoor, tabloides e outros veículos) ocupa lugar de destaque por se valer da linguagem verbal, orientando o sentido da própria imagem.

Qualquer texto é passível de possuir estratégias argumentativas, em maior ou menor grau. $\mathrm{O}$ anúncio publicitário pode superar qualquer outro. Na produção de um anúncio, há estratégias para espelhar, fundamentar ou "criar" o real: tudo para provocar a "venda" do que se está oferecendo por meio de despertar a carência do enunciatário para fazê-lo querer "comprar", conforme observaremos a seguir.

\section{O dialogismo e a construção do ethos no anúncio publicitário da marca OMO}

A chegada do sabão em pó ao Brasil ocorreu no final da década de 1950, o anúncio destacado a seguir (Figura 1) foi veiculado na mídia impressa, em um jornal da época, na década de 1960. Conforme podemos observar a partir do slogan "Omo lava mais branco" a sua motivação funcional era provar a eficiência nas referências à brancura, ao brilho etc.

Figura 1 - Anúncio 1

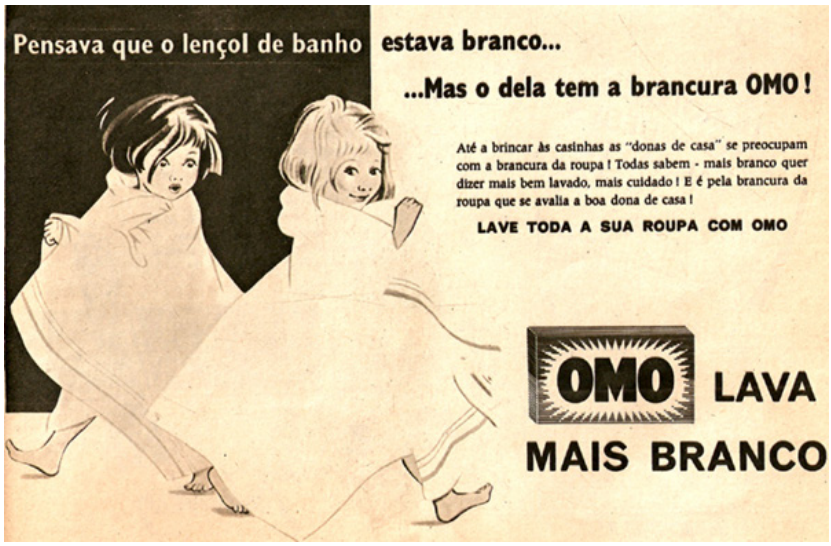

Fonte: Reprodução de anúncio disponível no site oficial da Unilever.

Já em 2007, a marca mudou a sua motivação funcional para enfocar o lado emocional dos consumidores difundindo, nos mais variados meios de comunicação, anúncios publicitários que utilizavam o slogan "Porque se sujar faz bem". O slogan induz à formulação de duas vertentes interpretativas. Na primeira, se constrói como um contra-argumento para o ponto de vista - conservado na tradição das famílias brasileiras - que afirma que se sujar faz mal, no que concerne ao bem-estar das crianças. A segunda vertente interpretativa, que é a principal, está relacionada à cena genérica, ou seja, trata-se de um anúncio publicitário de uma marca muito popular de sabão em pó: aqui, o enunciador é a própria empresa proprietária da marca, que afirma através do slogan, para um público-alvo (as mães de crianças pequenas), que "se sujar faz bem", logo, as crianças podem sujar suas roupas, que serão lavadas pelo sabão em pó que "que lava mais branco". Assim, não deve haver preocupação com as roupas sujas das crianças, uma vez que todo o trabalho para a limpeza ficaria a cargo do produto.

\footnotetext{
1 Disponível em: http://www.unilever.com.br/aboutus/historia das marcas/ Omo/omo anuncioimpresso 1957.aspx. Acesso em: 31 maio 2018.
} 
Figura 2 - Anúncio 2

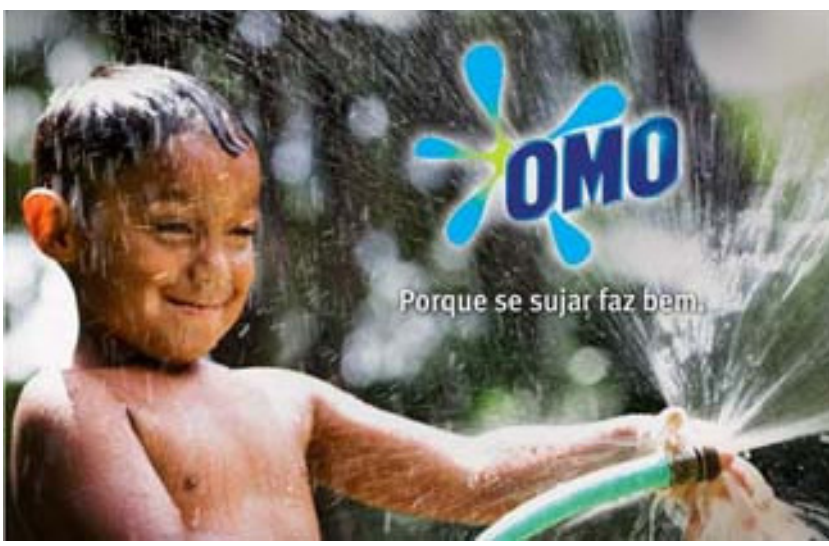

Fonte: Reprodução de anúncio disponível no site Garotas de Propaganda.²

No ano de 2007, a marca OMO completou cinquenta anos de atuação no mercado brasileiro:

O ano de 2007 foi marcado pelo aniversário de 50 anos de OMO no Brasil e um início de estudo sobre a infância do ponto de vista das mães, realizado em 10 países. Conjuntamente a esse estudo, OMO também realiza fóruns e eventos sobre a importância da atividade de brincar para o melhoramento do aprendizado, com a ajuda de especialistas de diversas áreas de conhecimento vizinhas, de diversas partes do mundo, sendo que seus resultados e debates são divididos com pais, psicólogos e educadores (UNILEVER) (GOMES, 2009, p. 387).

Dessa forma, o novo slogan "Porque se sujar faz bem" é legitimado através de fatores como: o tempo de circulação da marca OMO no mercado brasileiro, tal fato confere que o produto alcançou um lugar estável no nicho de sabão em pó; outro fator relevante para a legitimação do slogan é o investimento da empresa em pesquisas sobre a infância em diversos países, o que mostra a grandiosidade e o poderio da Unilever, uma multinacional de grande porte. Pode-se perceber que a empresa, também procura legitimar seu posicionamento em outros discursos, como o científico, o familiar e o educacional, para credibilizar o seu argumento "Porque se sujar faz bem".

De acordo com Bakhtin (1981), a língua é vista como um fenômeno social, histórico e ideológico, por consequência, "a comunicação verbal não poderá jamais ser compreendida e explicada fora desse vínculo com a situação concreta" (BAKHTIN, 1981, p. 124). É impossível analisarmos os dois anúncios acima sem levarmos em consideração fenômeno social, histórico e ideológico. Vimos que os dois textos foram veiculados em épocas distintas, o primeiro anúncio foi veiculado

\footnotetext{
2 Disponível em: https://garotasdepropaganda.wordpress.com/2009/08/11/ porque-se-sujar-faz-bem/. Acesso em: 10 out. 2019.
}

no século passado, década de 1960 . Neste momento histórico, havia uma situação social distinta da atualidade. As mulheres desempenhavam duas funções básicas: eram responsáveis pelas atividades domésticas e pelos cuidados com a família. Uma dona de casa ideal era aquela que desempenhava todas essas atividades com zelo e atenção, qualidades exigidas e esperadas de uma mulher pela sociedade da época. As mulheres já eram educadas desde cedo para ser uma boa dona de casa. Esse papel da mulher fazia parte da ideologia da década. $E$ as marcas de produtos para o lar já flagravam essa ideologia: "É pela brancura da roupa que se avalia uma boa dona de casa". Conforme podemos observar no primeiro anúncio.

$\mathrm{O}$ anúncio 1 dialogava com esse público e tentava persuadir através da exposição das necessidades desse interlocutor, ou seja, "apenas o OMO é capaz de dar a brancura ideal em suas roupas", "para ser uma boa dona de casa é preciso adquirir o produto OMO".

Décadas mais tarde, no ano 2000, o momento histórico, social e ideológico se transforma, a preocupação da dona de casa já não é a mesma do século passado. As mulheres adquirem independência, a sociedade passa a cobrar não apenas a mulher zelosa, que cuida da casa e da família, mas passa a cobrar, também, a sua inserção no mercado de trabalho. Desse modo, outros valores passam a ser colocados como importantes: a boa educação dos filhos. Ou seja, a mãe já não se restringe mais aos cuidados domésticos, pois assume outro papel fora de casa, o tempo para cuidar dos filhos e da casa já não é o mesmo. Acompanhando essa mudança sócio-histórica e ideológica, os produtos domésticos passam a se direcionar para esse novo público, com mais atividades acumuladas: profissionais, mães, donas de casa, mas sem esquecer a preocupação pela boa educação dos filhos.

Figura 3 - Anúncio 3

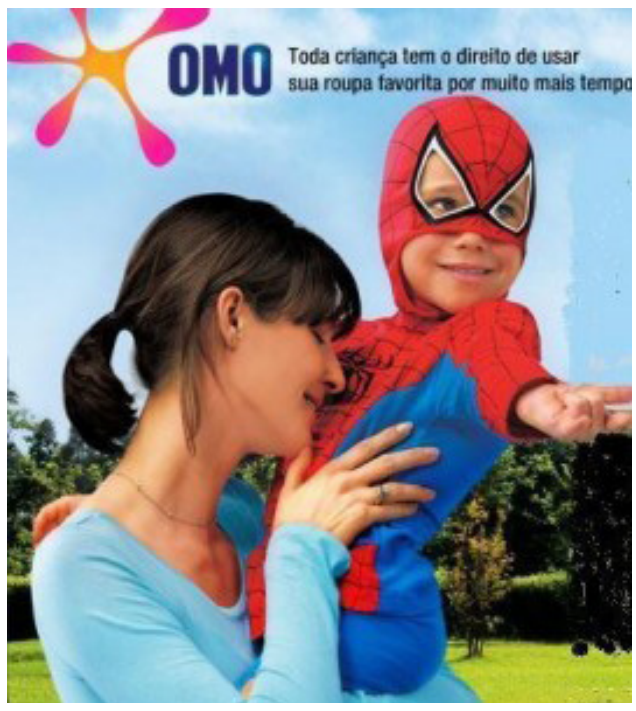

Fonte: Reprodução de anúncio veiculado na Revista Veja, 11 set. 2010. 
Então, em 2007 a estratégia de marketing do produto OMO teve a sua motivação funcional alterada, conforme já afirmamos, para enfocar o lado emocional de um novo público preocupado com a educação dos filhos, utilizando o slogan "Por que se sujar faz bem".

A campanha supracitada, anúncio 3 (Figura 3), revela uma nova fase de abordagem publicitária da marca, que tenta propor uma nova forma de relação entre mães e filhos, segundo a qual as mães devem passar a participar mais ativamente da educação e da formação de suas crianças.

O discurso exposto se insere no gênero anúncio e no discurso publicitário, que é altamente argumentativo e tem como objetivo persuadir as pessoas a adquirirem o produto que está anunciado - o detergente em pó OMO. Contudo, não será com a cena genérica e a cena englobante, ou seja, o quadro cênico que o leitor irá se envolver diretamente, mas sim com a cenografia, ou seja, com o espaço de enunciação criado para camuflar essa relação de compra e venda.

O leitor da Revista Veja, em que é apresentado o anúncio, encontra-se simultaneamente nas três cenas: cena englobante, cena genérica e cenografia. Ele é interpelado ao mesmo tempo como consumidor (cena publicitária), como leitor da revista (cena do gênero discursivo) e como uma mãe ou pessoa responsável pela criança (cena construída pelo texto).

No anúncio 3 (Figura 3), o enunciador, dirigindo-se ao leitor da Revista Veja, faz com que esse se coloque na posição de uma mãe, consciente da importância da atividade de brincar para a criança, já que o coenunciador é levado pelo enunciador a incorporar o papel de uma pessoa responsável por uma determinada criança e seu bem-estar, e não o de um consumidor preocupado em escolher um detergente em pó.

$\mathrm{O}$ enunciador - $\mathrm{OMO}$ - propõe ao coenunciador mãe (ou qualquer pessoa que se encontre em uma relação de responsabilidade por uma criança) um acordo, ou seja, proporcionar o melhoramento do aprendizado através da atividade de brincar. Desse modo, o enunciador vai estabelecer uma relação de comunicação (ou de manipulação) com o coenunciador, fazendo com que o leitor perceba que, se adquirir o produto, ele ficará tranquilo, pois não terá as roupas de sua criança manchadas devido à consequência da ação das brincadeiras, visto que o detergente em pó irá ser o responsável por remover todas as manchas. Desse modo, a criança brincará livremente, sem a preocupação dos pais com suas vestimentas, conforme afirma o enunciado: "Toda criança tem o direito de usar sua roupa favorita por muito mais tempo". Em suma, o coenunciador não será levado apenas a querer adquirir o produto, mas também a dever fazê-lo como modo eficaz de proporcionar momentos felizes para o seu filho, como, por exemplo, passar mais tempo com a sua roupa favorita.

Uma vez que o leitor interpreta a persuasão do enunciador, acredita nele e aceita, ocorre a incorporação, ou seja, a ação do ethos construído no enunciado sobre o coenunciador.

$\mathrm{Na}$ cenografia criada pelo anúncio 3 (Figura 3), podemos perceber, através do nosso conhecimento de mundo, que se trata de uma mãe segurando o seu filho no colo. Há a representação da mãe: a construção de um ethos a partir da imagem de uma mulher abraçada com seu filho, transparecendo cuidado e carinho ao cheirar a sua roupa. O ethos do enunciador (a empresa Unilever, proprietária da marca $\mathrm{OMO}$ ) é construído com base em valores como a responsabilidade e a competência, logo é um ethos que se apresenta através da imagem de uma empresa multinacional preocupada com o bem-estar das famílias consumidoras de seu produto, o sabão em pó $\mathrm{OMO}$

A figura mulher, a mãe, na cenografia do anúncio 3 (Figura 3), representa uma relação saudável (como é esperada pela sociedade) entre mãe e filho. Há a figura da criança, o filho, aquele que deve ser protegido e cuidado pela mãe, e a representação do próprio produto, em forma de texto, através da logomarca "Omo", localizada na parte superior da anúncio. O ethos do enunciador é construído na cenografia do anúncio através das representações tanto da mãe, quanto do filho e da logomarca do sabão, que, através do texto "Toda criança tem o direito de usar sua roupa favorita por muito mais tempo", se coloca quase como um amigo íntimo, preocupado com o bem-estar da família e capaz de oferecer o meio pelo qual a criança poderá brincar e se divertir sem o receio da mãe em ter as roupas do seu filho manchadas pelas brincadeiras de criança, pois a empresa, responsável e preocupada com o bem-estar dos filhos de seus consumidores, trabalha há muito tempo aperfeiçoando um produto que irá ajudar a proporcionar esse bem-estar, logo, pode-se esperar que seus argumentos sejam verdadeiros.

Vejamos a descrição dessa cenografia:

$\mathrm{RESPONSABILIDADE} \rightarrow \mathrm{PREOCUPAÇÃO} \rightarrow \mathrm{OMO} \rightarrow \mathrm{REALIZAÇÃO}$

De acordo com o esquema acima, podemos tecer a seguinte interpretação: a mãe encontra-se em uma relação de RESPONSABILIDADE por alguém, na cenografia, a criança, seu filho, ou seja, cuidá-lo e protegê-lo. Devido a essa relação, há a PREOCUPAÇÃO da mãe em evitar que o filho se suje e estrague as suas roupas. Contudo, o produto OMO será o facilitador, ou seja, aquele que irá tornar possível as brincadeiras das crianças, ou seja, essa REALIZAÇÃO, sem que, para isso, tenha que haver manchas em suas roupas. 
Desse modo, vemos que o anúncio manipula a mãe pela sedução, pois o enunciador apresenta um valor que o coenunciador acredita ser importante e necessário para oferecer à mãe, ou seja, a diversão do filho sem a preocupação das manchas. A marca ainda ressalta a importância do ato de brincar como forma de desenvolver o aprendizado do filho, como já comentamos. Em suma, esse valor (diversão das crianças, desenvolvimento do aprendizado, ausência de manchas em suas roupas) só será possível de ser alcançado através do detergente em pó OMO, ou seja, se a mãe adquirir o produto.

O leitor é levado a se identificar com o ethos da mãe. Por meio dessa identificação, o coenunciador experimenta o sentimento de "formar corpo", conforme afirma Maingueneau (2001), com outras mulheres que tenham um filho e querem proporcionar momentos de diversão sem a preocupação com as manchas. Conforme vimos, as publicidades veiculadas em mídia impressa são usualmente dotadas de linguagem verbal e não verbal (visual), é relevante observar a articulação entre essas duas linguagens para notar como as estratégias manipulativopersuasivas utilizadas pelo enunciador persuadem seu coenunciador.

No anúncio 3 (Figura 3) da propaganda, podemos perceber que o enunciador confronta o coenunciador com a seguinte afirmação: "Toda criança tem o direito de usar sua roupa favorita por muito mais tempo" e ao lado do enunciado destaca a marca OMO, ressaltando as cores fortes presentes no anúncio que fazem parte da logomarca do produto.

É importante ressaltarmos que cada elemento no texto publicitário não é escolhido aleatoriamente, mas, sim, com o objetivo de construir o discurso persuasivo. Entre os elementos encontrados no texto que exercem essa função, destaca-se, por exemplo, o sintagma "toda criança" ao optar pela escolha do pronome "toda", inclui toda a categoria "criança" como beneficiários da ação da construção verbal. E o agente que irá proporcionar essa ação "direito de usar sua roupa favorita por muito mais tempo" é o produto OMO, ou seja, a marca se coloca como responsável em proporcionar "muito" mais tempo de lazer à criança.

Conforme já afirmamos, os textos publicitários têm por objetivo convencer o consumidor à aquisição do produto. Não podemos deixar de ressaltar a importância da comunicação gestual presente na imagem representando a função emotiva. Decorre daí o caráter fortemente emocional e passional da comunicação gestual, em detrimento do racional e do inteligível, conforme afirma Barros (2010).

A comunicação gestual entre a criança e a mãe estabelece-se, na propaganda em destaque, pelo olhar, pelo movimento da cabeça e pelo sorriso. A gestualidade com função emotiva ou atributiva é bem explorada no anúncio examinado. Trata-se de gesticulação, sobretudo, do rosto, e que comunica emoções, sentimentos. No anúncio da marca $\mathrm{OMO}$, são principalmente alegria, felicidade e prazer (por movimentos da boca, um sorriso, e olhos da criança) pela satisfação que sente ao ter a sua diversão realizada. O olhar e o sorriso da criança são elementos bem significativos e que são postos também em destaque na imagem, o leitor ao observar a imagem é envolvido por esse sorriso, representando toda a alegria da criança por ter realizado a sua brincadeira junto de sua mãe despreocupada.

A gestualidade representada no nível da enunciação do anúncio tem, assim, papel retórico fundamental na comunicação persuasiva desse texto: assegura relações intensas entre o enunciador e o coenunciador, estabelece o simulacro de uma comunicação em presença, aproxima os interlocutores corporal e sensorialmente e, mesmo, quase "oralmente", como defende Barros (2010).

\section{Considerações finais}

A aplicação de alguns conceitos da análise do discurso, como dialogismo e ethos, vem a contribuir, sobremaneira, para uma maior compreensão textual. Assim, o mapeamento sob esse aspecto apresenta a riqueza de elementos significativos em um texto.

Essa teoria nos dá uma direção para buscar e analisar elementos escondidos nas profundezas textuais. Os anúncios utilizados nesta pesquisa são textos curtos e escritos de forma simples e, por isso, presta-se ao entendimento geral dos leitores; porém, com o olhar da Análise do Discurso para a propaganda, foi possível verificarmos que os elementos aí retirados remetem a uma profundidade interna do texto, onde foi possível observarmos o fazer argumentativo-persuasivo do enunciador através da articulação entre os elementos verbais e elementos contextuais.

Como o publicitário-anunciante sabe que não está faceaface com o leitor-consumidor e que também não pode forçá-lo a comprar o seu produto/serviço ou coagilo a manifestar um determinado comportamento, procura conquistá-lo e, para tanto, constrói a imagem de um ethos de tal modo que o interlocutor possa se identificar com essa imagem, na propaganda exposta em nossa análise, há a construção do ethos de uma mãe que quer proporcionar momentos felizes para o filho, mas sem se preocupar com as consequências dessas brincadeiras, como as manchas nas roupas. Desse modo, não será com o quadro cênico que o leitor-consumidor irá se envolver, mas com a cenografia criada pelo anúncio.

Por sua vez, o leitor/consumidor também aparece mascarado. $\mathrm{O}$ enunciador não se dirige diretamente 
ao leitor/consumidor, mas sim à imagem que faz dele, ou seja, ao coenunciador. Por exemplo, quando o coenunciador incorpora o estereótipo da mãe zelosa, que adquire o produto $\mathrm{OMO}$, o leitor-consumidor se identifica com essa imagem de boa mãe, que também passa a ser desejada pelo leitor/consumidor, mas para isso ele precisa comprar o produto. Dessa forma, o coenunciador se apresenta como alguém que tem uma necessidade e precisa preenchê-la. Aliás, o enunciador aparece como o agente único capaz de satisfazer assuas necessidades. Nesse jogo de máscaras enunciativas, são construídas as identidades dos interlocutores do discurso publicitário.

\section{Referências}

AMOSSY, Ruth. Da noção retórica de ethos à análise do discurso. In: AMOSSY, Ruth (org.). Imagens de si no discurso: a construção do ethos. São Paulo: Contexto, 2005. p. 9-28. https://doi.org/10.35501/dissol.v0i8.485

ARISTÓTELES. Arte poética e arte retórica. Rio de Janeiro: Ediouro, s.d.

AUSTIN, John Langshaw. Quando dizer é fazer: palavras e ação. Tradução de Danilo Marcondes de Souza Filho. Porto Alegre: Artes Médicas, 1990.

BAKHTIN, Mikhail. Marxismo e Filosofia da Linguagem. 6. ed. São Paulo: Hucitec, 1992.

BAKHTIN, Mikhail. Os gêneros do discurso. In:

BAKHTIN, Mikhail. Estética da Criação Verbal. 2. ed. São Paulo: Martins Fontes, 1997. cap. p. 279-326. https://doi. org/10.22456/2594-8962.70365

BAKHTIN, Mikhail. Os gêneros do discurso. In: BAKHTIN, Mikhail. Estética da criação verbal. Trad. Maria Ermantina Galvão G. Pereira. 3. ed. São Paulo: Martins Fontes, 2000. p. 277-326. https://doi.org/10.22456/2594-8962.70365

BAKHTIN, Mikhail. Problemas da Poética de Dostoiévski. 3. ed. Traduzido por Paulo Bezerra. Rio de Janeiro: Forense Universitária, 2002.

BRAIT, Beth. Ironia em perspectiva polifônica. Campinas, São Paulo: Unicamp, 1996. https://doi.org/10.18309/anp. v1i3.267

BRAIT, Beth. Mikhail Bakhtin: o discurso na vida e o discurso na arte. In: DIETZSCH, Mary Julia Martins. (org.). Espaços da linguagem na educação. São Paulo: Humanitas, 1999. p. 11-39.

BARROS, Diana Luz Pessoa de. Interação em anúncios publicitários. In: PRETI, D. (org.). Interação na fala e na escrita. 2. ed. São Paulo: Humanitas, 2003.

BARROS, Diana Luz Pessoa de. Os sentidos da gestualidade: transposição e representação gestual. CASA, [S. l.], v. 8 n. 2, dez. 2010. https://doi.org/10.21709/casa.v8i2.3318
CARVALHO, Nelly de. Publicidade: a linguagem da sedução. 3. ed. São Paulo: Ática, 2000.

DUCROT, Oswald. O dizer e o dito. Campinas: Pontes, 1987.

GOMES, Jaqueline Maria de Moraes. O ethos do enunciador na criação publicitária. In: ENCONTRO REGIONAL DE ESTUDOS DA IMAGEM, 2., 2009. Anais [...] Londrina, 2009, p. 385-389. Disponível em: http://www.uel.br/eventos/ eneimagem/anais/trabalhos/pdf/Gomes_Jaqueline.pdf. Acesso: 10 out. 2019

MAINGUENEAU, Dominique. Cena enunciativa em análise do discurso. 3. ed. Campinas: Pontes/Editora Unicamp, $1997 \mathrm{a}$.

MAINGUENEAU, Dominique. Novas tendências em análise de discurso. São Paulo: Pontes, 1997b.

MAINGUENEAU, Dominique. Análise de textos da comunicação. 3. ed. São Paulo: Cortez, 2001. https://doi. org/10.18309/anp.v1i12.518

MAINGUENEAU, Dominique. Gênese dos discursos. Curitiba: Criar, 2005.

REVISTA VEJA. São Paulo: Abril, edição 2100, 11 set. 2010.

Recebido em: 31/5/2018.

Aprovado em: 12/9/2019.

Publicado em: 21/12/2019.

Autoras:

Juliana GeÓrgia GonÇAlves de AraúJo

Doutora e professora assistente, Universidade da Integração Internacional da Lusofonia Afro-Brasileira, Redenção, CE, Brasil Orcid: http://orcid.org/0000-0002-0116-4918

E-mail: jgeorgia.araujo@gmail.com

Lia RAQUEL VIEIRA DE ANDRADE

Doutora e professora adjunta, Universidade da Integração Internacional da Lusofonia Afro-Brasileira, Redenção, CE, Brasil Orcid: http://orcid.org/0000-0003-4392-4329

E-mail: lia.andrade@unilab.edu.br

Endereço: Universidade da Integração Internacional da

Lusofonia Afro-Brasileira

Av. da Abolição, 3 - Centro

62790-000, Redenção, CE, Brasil 